\title{
GENERATION Z: EXPLORING PERSONALITIES, INTERESTS AND INFLUENCES IN YOUNG DESIGNERS
}

\author{
Franziska CONRAD ${ }^{1}$ and Gary UNDERWOOD ${ }^{2}$ \\ ${ }^{1}$ Arts University Bournemouth \\ ${ }^{2}$ Bournemouth University
}

\begin{abstract}
Product designers - whether students or professionals - are a diverse group of individuals with mixed abilities in a variety of skills. As an integral element of design education at undergraduate level, design projects in particular appear to highlight this diversity of characteristics. At Bournemouth University the level 5 and 6 design projects have proved noticeably enlightening in differentiating between students' innate strengths and weaknesses. As a result, a number of personality types were identified; the Doers; the Dreamers; the Ideators; the Negotiators; the Visionaries; and the Whatevers.

Personality analysis tools such as the Myers Briggs Type Indicator (MBTI) and the NEO Personality Inventory have become established in the workplace, and attempts have been made to apply such systems to the design studio. In addition, the identification of individual learning styles - and corresponding teaching styles - has become a core feature in education. This paper investigates whether the identification of defined personality types and traits within project-based product design education is justified, and to what extent such characteristics may be affected by external influences. Drawing on a survey conducted with undergraduate students at levels 4,5 and 6 - as well as design professionals the interests, inspirations and aspirations that may help to shape designer personalities are explored, and the results shed new light on the emergent characteristics of tomorrow's designers. In a world in which the role of team players is becoming more important, the authors discuss the differing student strengths and weaknesses reflected in the survey, and whether a greater understanding of the influences and ambitions of Generation $\mathrm{Z}$ could help to address the current and future skills shortage in product design.
\end{abstract}

Keywords: Product design education, design projects, personality analysis, design characteristics, Generation Z

\section{INTRODUCTION}

The use of personality tests as a professional tool within the workplace is long established and increasingly commonplace. Arguably the most prevalent of these assessment tools is the Myers-Briggs Type Indicator (MBTI). The MBTI's relatively straightforward system of classifying individuals as one of 16 personality types based on binary options (e.g. Extrovert or Introvert; Thinking or Feeling) has proved massively popular in the workplace. It is used by countless organisations around the world including around 80 percent of Fortune 500 companies in the US [1].

Despite MBTI's prevalence, a number of alternative tests and scales have been posited, many of which aim to examine personality traits rather than types. Unlike the binary choices of personality type analysis such as MBTI, trait analysis attempts to measure how highly an individual performs on a graded scale in five key character attributes. The most widely supported and established of these trait analysis tools is the Revised Neuroticism-Extraversion-Openness Personality Inventory (NEO-PI-R), a descendant of the 'Big Five' or 'Five Factor Model' classification system [2].

Research into the use of personality analysis tools in business has been widespread for almost 80 years. Opinion has been extremely divided on which form of analysis is more useful, and whether either form of analysis can provide genuine insight into the future performance of employees. It is interesting to note that none of this controversy appears to have dimmed the popularity of MBTI in particular, most probably because of the simplicity of its approach [3]. 


\subsection{Personality analysis in design education}

Both MBTI and NEO-PI-R have been applied to students, and (particularly useful in the context of this paper) there is literature which investigates the application of personality analysis to design students. Most of this research focuses on a possible link between creativity and personality type/traits [4][5], or on the use of personality analysis to determine students' learning preferences. Durling, Cross \& Johnson [6] assess how art and design students' MBTI personality types differ from other sectors of the population and suggest which different learning styles will suit different personalities. While acknowledging that all groups feature a mix of personalities - with associated different preferred learning styles - they propose some general guidelines for teaching methods that are most likely to suit design students. Carey \& Barthalmeh [7] present a wealth of research both critical and supportive of learning style influenced teaching and conclude that there is little evidence to support "the meshing hypothesis", i.e. a correlation between specialised instruction and improved standards of learning. Instead they propose that analysis of personality type "might be a more useful avenue to explore in regard to improving student learning outcomes". Their analysis concludes that personality type analysis such as MBTI is preferable to trait analysis in this regard as it lacks the in-built value judgement of a system such as NEO-PI-R.

However, these personality analysis methods are a product of psychology. The Myers-Briggs Type Indicator was derived from theories proposed by the founder of analytical psychology, Carl Jung [8]. The Neuroticism-Extraversion-Openness Inventory - later revised as NEO-PI-R - was initially developed as a tool for clinicians and psychoanalysts. Likewise, learning theories were a mainstay of psychology before being utilised in education for the development of teaching styles. As such, they are not tailored to a specific use outside of psychology and offer debatable benefit to design education. While all of these tools and theories focus on a student's innate characteristics and preferences, there is (purposely) little consideration for external influences, goals and interests. For that reason, the authors decided to try and investigate student designer personalities in a different way.

\section{THE SURVEY}

Project based teaching has long been established as an important and valuable part of design education. At the end of a design degree a student will have been exposed to a broad spectrum of design practice and will have had the opportunity to develop as a designer in their own right with a skill set to match their chosen course direction, motivation and exposure to design and manufacturing environments. Moholy-Nagy's [9] vision of design education finds that a balance between the natural skills of the students and the contemporary environment still has relevance in 2019.

At Bournemouth University (BU), BA/BSc/MDes Product Design students engage in projects at levels 4, 5 and 6 to develop a wide range of design-based skills. During the course of both the level 5 and level 6 projects it had been noted that students seemed to show a wide divergence in how they coped at the various stages in the project. Over the past five years, a variety of personality types were identified and used in conversation with students and in feedback (as well as in discussions with other design educators) and the informal use of these personality types seemed to help both students and lecturers understand different design strengths and weaknesses better. Six types were identified:

- The DOER: Likes direction \& problem definition before starting out on a project. Struggles to get started with ideas \& projects.

- The DREAMER: Has lots of ideas all the time but doesn't really like the research part and never really gets past the initial concept stage.

- The IDEATOR: Enjoys the front-end design process, finding problems, research, concept development, testing. Sometimes struggles to finish things.

- The NEGOTIATOR: Likes to question design parameters and has a tendency to try and renegotiate at all stages of the project. Has a tendency to take personal initiative beyond set design parameters which might not always be in the best interests of the client/project outcome.

- The VISIONARY: Always one step ahead, looking for opportunities, pushing boundaries, challenging views, ready to take a risk.

- $\quad$ The WHATEVER: Just gets on with it. Will do whatever is enough to get through.

Following this observation, a survey was created in which students were asked with which group they identified. In addition, a wide range of additional questions were included to try to determine the influences, interests, expectations and aspirations of the cohort and whether these factors were in any 
way reflective of their self-identified character types. The results shone new light on not only character types, but also on the changing make-up of the current cohort of product design undergraduates at BU, and how this relates to the responses of product design professionals.

\subsection{Survey Results}

The survey had a total of 79 respondents; 67 students - spread fairly evenly over the four years of BU's undergraduate Product Design course - and 12 Product Design professional practitioners. The gender split was broadly representative of the course: 60 males to 18 females, and one student identifying as transsexual. The responses were analysed according to gender, year group and personality type. The following represents some of the key findings from the survey:
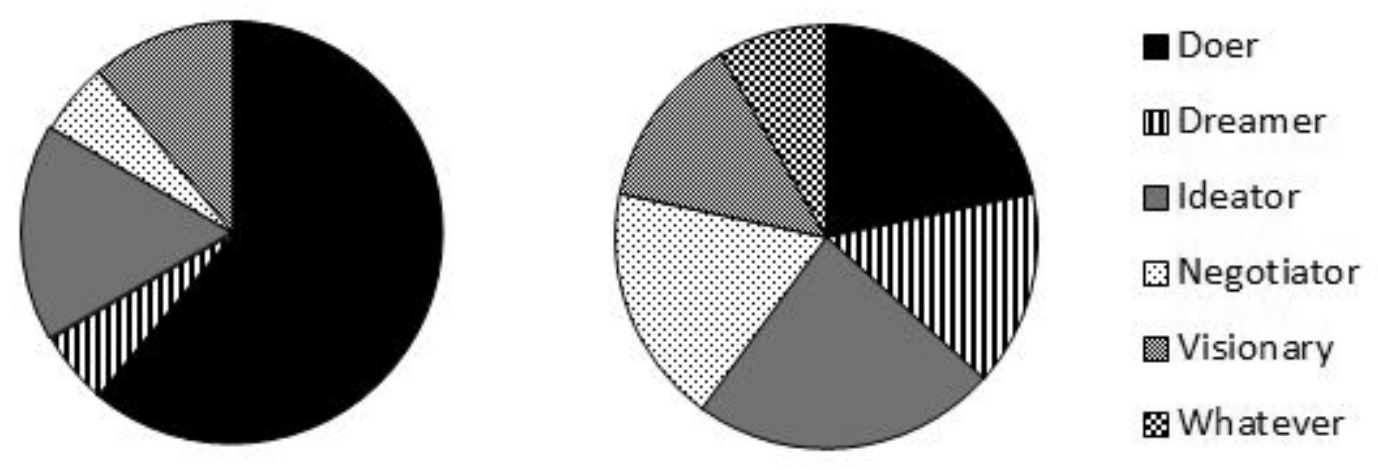

Figure 1. Personality types of BU PD students by gender: female (left) and male

\subsubsection{Personality types: Females are overwhelmingly Doers}

- While males were fairly equally distributed between the six personality types, $61 \%$ of females identified themselves to be Doers (Figure 1).

- Only one female student identified as a Negotiator, compared to one fifth of males, and no females identified as Whatevers.

- Although Doers represented the most common personality type for students, practitioners were more likely to identify as Ideators.

- $\quad$ No practitioners called themselves Dreamers.

\subsubsection{Choosing to study Product Design: Dreamers like making things more than Doers}

- The vast majority of Dreamers (90\%) said they chose to study a degree in Product Design because they liked making things - more than any other group.

- The most popular male response was feeling passionate about design; for females it was because they like making things.

- Females were almost twice as likely as males to have been influenced in their decision by a teacher.

\subsubsection{Interests: Art is out of fashion}

- Shown a list of 22 design-related topics, all personality types registered very high levels of interest in technology, rapid prototyping, 3D CAD modelling, model making and aesthetics.

- All groups showed very little interest in art, fashion, print or typography.

- Negotiators differed from all other groups in registering little interest in sustainability, sketching and not-for-profit design.

- Male respondents declared a significantly greater interest in technology and robotics than females; conversely females were much more likely to have an interest in sustainability and inclusive design than males.

\subsubsection{Inspirations: Global tech entrepreneurs are the biggest inspiration}

- By far the most common answer to the question 'Who inspires you' was PayPal and Tesla entrepreneur Elon Musk. James Dyson, Jonathan Ive, Dieter Rams and Steve Jobs also featured high amongst the 62 individuals named by respondents. 
- These names were virtually absent from female responses; the most common inspiration for women was 'no-one in particular', followed by nature, colleagues and lecturers.

- Only six female inspirational figures appear, and the only female designers mentioned - Ray Eames and Rowena Kostellow - passed away more than thirty years ago.

\subsubsection{Areas of influence: Education is ripe for positive design change}

- In response to the question 'Which areas do you feel you could influence for the better throughout your career as designers' most personality types - two-thirds of respondents overall - believed education to be the most likely area for positive change.

- Visionaries see massive potential in space exploration (80\%), while Negotiators ranked raw material depletion highest.

\subsubsection{Briefs: A given brief is best}

- The personalities were split on whether they prefer to work to a given brief or create their own. Doers, Ideators and Negotiators prefer a brief; Dreamers, Visionaries and Whatevers prefer not.

- Overall two-thirds of students preferred to work to a given brief, and female respondents in particular registered a strong dislike (78\%) to having to come up with their own brief.

\section{DISCUSSION}

The Design Council report The Design Economy 2018 sheds considerable light on the current state of the design industry in the UK. Amongst its most startling and stark findings is the massive gender imbalance. Across the design workforce as a whole, only $22 \%$ is female, compared to $47 \%$ among the UK national workforce. And the poorest figures are reserved for product and industrial design: just 5\% of the workforce is female [10]. The Office for National Statistics also reveals a considerable gender pay gap in UK design, with product design again displaying the largest discrepancy: female product designers currently earn around $£ 7,000$ less than their male colleagues [11].

Our survey results indicate considerable differences between male and female responses in a number of areas, and while the reasons for the gender discrepancies in the design industry are many, some of the survey responses may be indicative of some of these issues.

For example, the much greater proportion of male Negotiators and Dreamers perhaps indicates the differences between male and female designers in the race for employment and promotion. Facebook's chief operating officer, Sheryl Sandberg, is critical of women's role in restricting their career progression, by "leaning back" during meetings, pushing less hard for promotion and being satisfied with less responsible roles at work [12]. Hewlett Packard's finding that men will apply for jobs they only feel $60 \%$ qualified for, whereas women tend to only apply if they fulfil $100 \%$ of the requirements, echoes this. Negotiators and Dreamers are more likely to aspire to things that (on paper) may be fanciful but can be achieved through argument and diplomacy.

US research by McKinsey [13] concluded that the gender employment gap was partly driven by a lack of role models, an issue highlighted by Buckley in 1989, and by many authors since. The lack of female inspiration figures reflected in our survey is a stark reflection of this. It could be argued that the gender imbalance in BU's product design teaching cohort (which currently includes only 5 female lecturers in a team of 23) may have contributed; but the survey responses show that the lack of female 'inspirations' is as marked for level 4 students as for level 6 . This would suggest that earlier influences have more bearing.

The predominance of global billionaire tech entrepreneurs amongst the male student responses is eye opening. Product design inspiration for young male designers appears to be dominated by tech companies such as Apple, Google and Microsoft that are not, by nature, design companies, but have instead utilised and adapted design thinking to amass massive global wealth [14]. This is also evident from the male survey responses relating to interests: technology, robotics and CAD were hugely popular. The results beg the question of whether the male product design cohort at BU aspire simply to be professional designers within a design agency, or whether their goals are more entrepreneurial, within a non-design industry, with a greater aspiration for wealth and global influence.

The 2018 Design Council report [10] also reveals that female design students tend to outperform their male colleagues at university and are significantly more likely to achieve a first or upper-second degree classification. This situation is echoed at BU, where the proportion of female students attaining a first or upper-second degree classification has surpassed males by an average of 9 percentage points over the 
past five years. This may be a reflection of BU's heritage as a former engineering college. The large proportion of female students who identified as Doers are likely to be better suited to the practical nature of BU's product design course than other personality types such as Dreamers or Visionaries. This could also be the reason why so many female students at BU are Doers; the University's technical bias is likely to attract young women with 'hard' design skills - as defined by Attfield [15] - rather than those who favour 'soft' design. This is particularly true in Bournemouth as the demand for 'soft' design is widely served by the neighbouring Arts University of Bournemouth.

The survey results relating to 'interests' expose this discrepancy between 'soft' and 'hard' design amongst the responders. 'Soft' design subjects, such as art and fashion, were unpopular across the student cohort while 'harder' design areas, such as technology and rapid prototyping, were much more popular. However, the female preference for subjects such as sustainability and inclusive design over technology and robotics would appear to put them at a disadvantage in the current design economy. According to another Design Council report [16], product and industrial design employers place physics, engineering and technology skills at the top of their requirements - much higher than skills such as creativity and user empathy. This suggests that women and Dreamers may struggle to find a place within the current design economy, and it is telling that there was a complete lack of Dreamers amongst the industry professionals in our survey. The industry emphasis on traditionally male, 'hard' design skills may well be a result of the gender split in Creative Directors - $89 \%$ of whom are male according to Kerning the Gap [17] - and may ultimately prove to be a flawed strategy. The onset of the Fourth Industrial Revolution, as defined by Schwab [18], requires designers with a greater sensibility for personalisation and environmental issues, and a shift in focus away from 'hard' skills [10].

\section{CONCLUSIONS}

It is important to note, of course, that these findings and comments are specific to product design at Bournemouth University. The design courses at BU (like any University) have developed in a particular way, as a result of specific pressures and changes. As a descendent of Bournemouth and Poole Technical College, BU has a tradition of teaching vocational, engineering-based courses, and the BA/BSc Product Design course was developed as a response to a falling demand for engineering courses. As a result, product design at $\mathrm{BU}$ is still more focussed on practical, technical skills than many similar courses at other universities. As such, it must be acknowledged that our findings may have limited relevance to other higher educational establishments. However, it should also be noted that many of the larger UK product design courses - such as at Loughborough and Brunel - have similarly emerged from an engineering-based heritage.

It should also be stressed that some students may have had a different understanding of the questions posed in the survey but without a follow-up it is hard to say how significant the discrepancies might be. Despite this, the authors believe that the survey has identified new insights into student design personalities. This is chiefly due to the fact that standard personality tests such as MBTI are designed to reflect the individual's inherent character; that is, primarily factors driven by 'nature'. In contrast, our survey concentrated more heavily on responses that are likely to be the result of a wide range of factors - such as social and economic background; educational background; peer influence; exposure to social media - alongside inherent character. This new approach therefore takes greater account of the influence of both 'nature' and 'nurture' in a designer's make-up.

By applying this shift in focus to a student's character, the survey shines a light on a number of issues. Of course, there are many differing factors that have influenced the student responses in the survey, and more research would be required to give additional clarification. However, the authors believe that the results indicate that social media and pre-university education currently play a major part in building the characteristics of our future design cohort. For example, both schools and social media are arguably driving a narrowing of experience and interests, and a greater degree of specialism. Simultaneously, exposure to tech-based media seems to be encouraging a rash of aspiring (male) design entrepreneurs, potentially at the expense of producing team players.

The identification of trends such as these is important for the UK design economy. Success in the Fourth Industrial Revolution depends on team players with diverse skills, experience and backgrounds [19]. The UK is currently experiencing a significant shortage of suitable product and industrial designers. The level of vacancies amongst design firms is higher than across the UK economy as a whole, and these vacancies tend to be classed as "hard to fill" due to the stringent requirements for skills, experience or qualifications [16]. By making use of new, improved methods of personality analysis and gaining a 
greater understanding of the interests, influences and aspirations of Generation Z, educators can help to ensure they are meeting the requirements of their future employers.

\section{REFERENCES}

[1] Bajic E. How the MBTI can help you build a stronger company. Available: https://www.forbes. com/sites/elenabajic/2015/09/28/how-the-mbti-can-help-you-build-a-stronger-company/\# 645c117ed93c [Accessed on 2019, 18 January], (2015) 28 September.

[2] Costa P.T. and McCrae R.R. The revised NEO personality inventory (NEO-PI-R). In Boyle G.J., Matthews G. and Saklofske D.H. (eds) The SAGE Handbook of Personality Theory and Assessment: Vol 2 - Personality Measurement and Testing, 2008, pp.179-198 (SAGE, London).

[3] Lloyd J.B. The Myers-Briggs Type Indicator and mainstream psychology: analysis and evaluation of an unresolved hostility. Journal of Beliefs \& Values, 2012, 33(1), 23-34.

[4] Durling D. Horse or cart? Designer creativity and personality. In Proceedings of the 5th European Academy of Design Conference, Barcelona, April 2003, pp.1-11.

[5] Chang C.C., Peng L.P., Lin J.S. and Liang C. Predicting the creativity of design majors based on the interaction of diverse personality traits. Innovations in Education and Teaching International, 2015, 52(4), pp. 371-382.

[6] Durling D., Cross N. and Johnson J. Personality and learning preferences of students in design and design-related disciplines. In IDATER 1996 Conference, Loughborough,1996, pp.1-7.

[7] Carey J. and Barthelmeh M.R. Teaching approaches and student learning: Personality type and design studio. Available: https://researcharchive.lincoln.ac.nz/handle/10182/7214 [Accessed on 2018, 8 December], (2016).

[8] The Myers \& Briggs Foundation. MBTI Basics. Available: https://www.myersbriggs.org/mymbti-personality-type/mbti-basics/home.htm?bhcp=1 [Accessed on 2019, 5 January 5], 2019.

[9] Moholy-Nagy L. Vision in motion, 1969 (Theobald \& Co., Chicago).

[10] Benton S., Miller S. and Reid S. The Design Economy 2018: the state of design in the UK. Available: https://www.designcouncil.org.uk/resources/report/design-economy-2018 [Accessed on 2018, 30 October], (2018).

[11] Dawood S. Gender equality design group Kerning the Gap expands across UK. Available: https://www.designweek.co.uk/issues/5-11-november-2018/gender-equality-design-groupkerning-the-gap-expands-across-uk [Accessed on 2018, 14 November], (2018) 7 November.

[12] The Economist. The feminist mystique - women and work. Available: https://www.economist.com/books-and-arts/2013/03/16/the-feminist-mystique [Accessed on 2018, 1 December], (2013) 16 March.

[13] Barsh J. and Yee L. Unlocking the full potential of women in the US economy. Available: https://genius.com/Joanna-barsh-unlocking-the-full-potential-of-women-in-the-us-economyannotated [Accessed on 2018, 4 December], (2011) 8 March.

[14] Mau B. Design is leadership (Unpublished essay). 24HRS2MassiveChange community workshop, Philadelphia, 2015.

[15] Attfield J. Form/female follows function/male: feminist critiques of design. In Walker J.A. (ed.) Design History and the History of Design, 1989, pp 199-225 (Pluto, London).

[16] Miller S. Designing a future economy: developing design skills for productivity and innovation. Available: https://www.designcouncil.org.uk/resources/report/ designing-future-economy-report [Accessed on 2018, 30 October] (2018).

[17] Kerning the Gap. Design world, we have a problem. Available: http://www.kerningthegap.com [Accessed on 2018, 3 December] (2018).

[18] Schwab K. The Fourth Industrial Revolution, 2016. (Penguin/World Economic Forum, Geneva).

[19] Snoad L. How to encourage diversity in the design industry. Available: https://www.creativebloq.com/features/how-to-encourage-diversity-in-the-design-industry [Accessed on 2018, 1 December] (2018). 